\title{
Constructing the Immersive Interactive Sonification Platform (iISoP)
}

\author{
Myounghoon Jeon ${ }^{1,2}$, Michael T. Smith ${ }^{3}$, James W. Walker ${ }^{2}$, and Scott A. Kuhl ${ }^{1,2}$ \\ ${ }^{1}$ Cognitive \& Learning Sciences, ${ }^{2}$ Computer Science, ${ }^{3}$ Electrical and Computer Engineering \\ Michigan Technological University \\ Houghton, MI, USA \\ \{mjeon, mtsmith, jwwalker, kuhl\}@mtu . edu
}

\begin{abstract}
For decades, researchers have spurred research on sonification, the use of non-speech audio to convey information [1]. With 'interaction' and 'user experience' being pervasive, interactive sonification [2], an emerging interdisciplinary area, has been introduced and its role and importance have rapidly increased in the auditory display community. From this background, we have devised a novel platform, "iISoP" (immersive Interactive Sonification Platform) for location, movement, and gesture-based interactive sonification research, by leveraging the existing Immersive Visualization Studio (IVS) at Michigan Tech. Projects in each developmental phase and planned research are discussed with a focus on "design research" and "interactivity".
\end{abstract}

Keywords: design research, interactive sonification, interactivity, visualization.

\section{Introduction}

Speech may be the most obvious means of communication using an auditory channel, whereas it is not the entirety of an auditory display just as text is not the only feedback in a visual channel. As compensating for the weakness of speech display (e.g., overall slowness [1] or interference with the current dialogue), auditory researchers have spurred research on sonification, which is defined as the use of nonspeech audio to convey information [2]. Since the birth of international community of auditory display (ICAD) [3], the taxonomy and theory of sonification have been developed, categorized, and refined [e.g., 4, 5, 6]. Audification is a common sonification technique, where a series of data is converted to samples of a sound signal [7]. It plays sounds without interruption, so it is just as hearing music. However, there is no interaction in such a type of sonification. With terms, 'interaction' and 'user experience' being pervasive, interactive sonification [8] has also been introduced and its role and importance has rapidly increased. Interactive sonification can be defined as "the use of sound within a tightly closed humancomputer interface where the auditory signal provides information about data under analysis, or about the interaction itself, which is useful for refining the activity" [9]. As an interactive sonification technique, parameter mapping [e.g., 4] has often been used, where data features are mapped onto acoustic attributes such as pitch, tempo, timbre, etc. Parameter mapping enables users to navigate through the (big) data, 
to adjust the mapping on prerecorded data, or to mold the sonification of data in real time [e.g., 10, 11]. Another framework for interactive sonification is model-based sonification [4]. In this approach, the data are used for a dynamic system setup. In this configuration, interacting with sonification models could have similar characteristics to interacting with physical objects such as musical instruments [9].

In the current paper, we introduce our unique sonification research platform, "iISoP" (immersive Interactive Sonification Platform). In this platform, researchers can conduct any type of sonification research, including audification, interactive sonification (parameter-based and model-based), as well as visualization, depending on their research goals. To double our research capability, we have made up of a multidisciplinary constituents, including cognitive scientists (empirical research based on embodied cognition paradigm), computer scientists (sonification and visualization system implementation), sound designers (sonification design), and visual and performing artists (performance and art research).

\subsection{Areas of Interactive Sonification}

Interactive sonification can be incorporated into multiple areas, such as user interface design, interactive learning, and novel user experience design including accessibility issues.

First, interactive sonification facilitates the design and implementation of natural user interfaces (NUIs) given that it implies dynamic elements [12]. As human-machine systems get more complicated, the demand for NUIs has increased (e.g., successive NUI workshops at the AutomotiveUI conference, 2011, 2012, 2013). When NUIs are rendered, however, they often lack interface visibility or physical feedback, which makes natural UIs unnatural [13]. Interactive sonification could offer appropriate feedback, and complement interface visibility by providing ambient affordance, or even guide users' activities [e.g., 14]. Research has supported that interactive sonification is an effective technique in exploring map data [15] and multivariate data in tangible computing [16], in desktop [17], or in ubiquitous computing contexts [18].

Second, interactive sonification enhances learning effects. For example, embodied interaction based on interactive sonification has shown effective in various learning areas. To illustrate, Antle et al. [19] developed a computational system that helps children understand musical concepts in the form of intuitive, physical analogs. Ferguson [20] showed the potential that interactive sonification can be used for communicating real-time acoustic analysis results to singers and instrumentalists. Howison et al. [21] also introduced the instructional design which helps students develop an understanding of proportional equivalence through perceiving, planning, and performing actions with the body with embodied-interaction based on interactive sonification. Recently, movement-sonification projects have also been introduced in sports training [e.g., aerobics, 22, rowing in a boat, 23]. All of these projects have suggested that fully engaging embodied interaction with sonified feedback is effective in enhancing the learning effects.

Finally, interactive sonification improves overall user experiences. To illustrate, recent research on the aquarium scene sonification project [24] made informal learning 
environment (e.g., aquariums, zoos, etc.) more accessible to diverse populations and improved user experiences, simply by adding sonification of audience's gestures, which leads to a musical fugue with fish movement-based sonification $[11,14]$. Results suggest that interactive sonification could improve visitors' learning and overall experiences by letting them to play a more constructive and interactive role.

\section{System Configuration and Visualizer}

For those promising applications of interactive sonification, we have developed a multi-purpose interactive sonification platform. We use 12 infrared cameras (using the Vicon tracker) attached around the Immersive Visualization Studio (IVS) walls to track users' location, movement, and gesture. The sonification system (based on JAVA, specifically, a JFugue library) generates speech, music, and sounds in realtime via a 5.1 speaker system, based on tracking data. 24 multivisions on a display wall visualize corresponding graphical user interfaces (GUIs) via OpenGL. More detailed system configuration is described below.

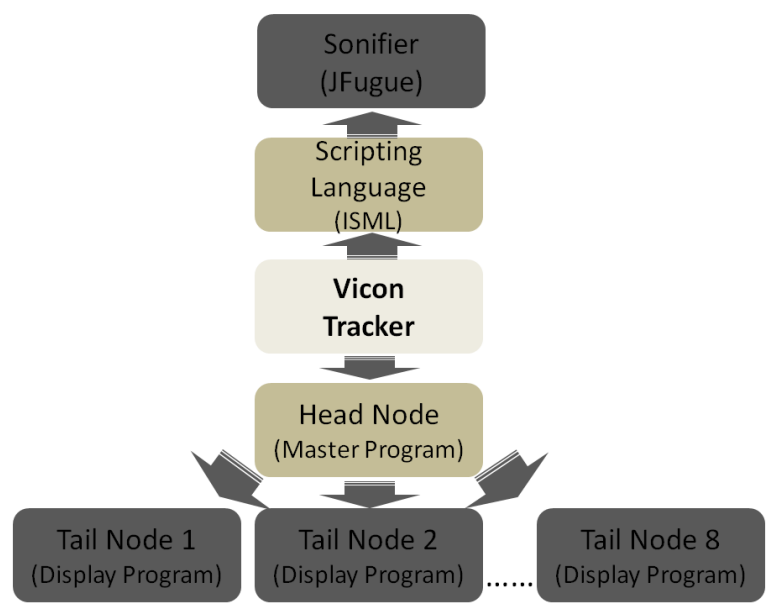

Fig. 1. The Vicon tracker sends the signal to (1) the visualizer (head node), which distributes it to 8 tail nodes, each of which is connected to 3 multivisions; and (2) the sonifier via the scripting language

The visualization component of the iISop (immersive Interactive Sonification Platform) provides visual feedback to users as an accompaniment to the audio component. Input data can be acquired by interfacing with the Vicon tracking system, or by reading data dumps in order to run prerecorded sessions. The visualization is shown on the display wall of $6 \times 442$ " television screens which are powered by a cluster of 8 computers, each with 2 high-end graphics cards. The Vicon tracking system consists of 12 infrared cameras with sub-millimeter accuracy running at approximately $120 \mathrm{~Hz}$. The system tracks special reflective markers, which can be attached to objects and configured to be tracked as a single entity. We have 
constructed six trackable objects for the use with the system: one wand, one hat for the head, and four straps, one for each wrist and ankle. Tracking these five parts of the body and a wand is sufficient to discern a wide variety of movements and allows for sophisticated data analysis.

The visualizer code is written in $\mathrm{C}++$, using the OpenGL framework. It works by running a master program on the head node of the cluster, then launching a copy of the display program on each tail node. The master either receives Vicon tracking data or reads from a prerecorded data dump and then, broadcasts the positional data of each object being tracked across the network via UDP (User Datagram Protocol) packets. The display programs receive these UDP packets and decode them to determine what data to display. In this way, the visualization remains synchronized across all nodes in the cluster. Each copy of the display program actually displays the same scene, but is given a different view frustum corresponding to its physical position on the display wall such that all of the programs running a single, coherent image in tandem display.

\section{$3 \quad$ Phased Sonification Projects}

Taking development complexity, interaction-mapping, and sonification-mapping into account, we have gradually developed our interactive sonification platform to be more fine-grained.

Table 1. Comparisons of sonifications among different developmental phases

\begin{tabular}{|c|c|c|c|}
\hline & Phase I & Phase II & Phase III \\
\hline Tracking & $\begin{array}{l}\text { Interactive map } \\
{ }^{\circ} \text { Location of the } \\
\text { wand }\end{array}$ & $\begin{array}{l}\text { Big instruments } \\
{ }^{\circ} \text { Movement of the users' } \\
\text { ankles or wrists }\end{array}$ & $\begin{array}{l}\text { Interactive sonification } \\
\text { Location, move- } \\
\text { ment, and gesture } \\
\text { of users' whole } \\
\text { body }\end{array}$ \\
\hline $\begin{array}{l}\text { Sound Generat- } \\
\text { ed }\end{array}$ & $\begin{array}{l}{ }^{\circ} \text { Pre-recorded wav } \\
\text { file (speech) }\end{array}$ & $\begin{array}{l}{ }^{\circ} \text { General MIDI (frequen- } \\
\text { cy) }\end{array}$ & $\begin{array}{l}\text { Virtual instru- } \\
\text { ments (e.g., Korg } \\
\text { Legacy Cell) }\end{array}$ \\
\hline $\begin{array}{l}\text { Sonification } \\
\text { Information }\end{array}$ & $\begin{array}{l}\circ \text { Same across } \\
\text { languages }\end{array}$ & $\begin{array}{l}\text { Musical frequency or } \\
\text { type of instrument }\end{array}$ & $\begin{array}{l}\text { Multiple sound } \\
\text { profiles }\end{array}$ \\
\hline $\begin{array}{l}\text { Sonification } \\
\text { Mapping }\end{array}$ & $\begin{array}{l}{ }^{\circ} \text { Horizontal Loca- } \\
\text { tion: Language } \\
{ }^{\circ} \text { Distance to Map: } \\
\text { Amplitude } \\
{ }^{\circ} \text { Wand flip: Gend- } \\
\text { er of voice }\end{array}$ & $\begin{array}{l}{ }^{\circ} \text { Horizontal Location: } \\
\text { Musical scale } \\
{ }^{\circ} \text { Distance to Map: Whole } \\
\text { (white)/semi (black) key, } \\
{ }^{\circ} \text { Hopping height: Veloci- } \\
\text { ty }\end{array}$ & $\begin{array}{l}\text { - Many to many } \\
\text { mappings }\end{array}$ \\
\hline $\begin{array}{l}\text { Visualization } \\
\text { Mapping }\end{array}$ & $\begin{array}{l}{ }^{\circ} \text { Distance to Map: } \\
\text { Zoom }\end{array}$ & $\begin{array}{l}\text { Horizontal Location: } \\
\text { Highlight of the keyboard }\end{array}$ & $\begin{array}{l}\text { Many to many } \\
\text { mappings }\end{array}$ \\
\hline $\begin{array}{l}\text { Level of Interac- } \\
\text { tivity }\end{array}$ & ${ }^{\circ}$ Reactivity & ${ }^{\circ}$ Reactivity & ${ }^{\circ}$ Full Interactivity \\
\hline
\end{tabular}




\subsection{Interactive Map}

Overall Concept. Because there was no sound equipment or software in the original Immersive Visualization Studio at Michigan Tech, we first developed an interactive map for Michigan Tech introduction as a sonification test bed. Users can listen to the pre-recorded (i.e., wave files) MTU introduction in multiple languages (e.g., USA English, UK English, Hindi, Chinese, Japanese, Korean, German, French, Spanish, Persian, etc.) based on their location in front of the big world map (Fig. 2). Depending on their distance from the map, the amplitude of voice clip changes (e.g., $6 \mathrm{~dB}$ increases when the user approaches the map by one unit) with the automatic zoom function of the visual map. In addition, depending on their horizontal location, panning of the sound is applied using a 5.1 speaker system. As a basic platform, this phase has a discrete oneon-one mapping between users' location and speech sounds. Information given by the sound (Michigan Tech introduction) is always the same across users' locations, but only the format (language) changes. This can be called a "responsive" system [25], rather an interactive system because it involves only a one- way communication.

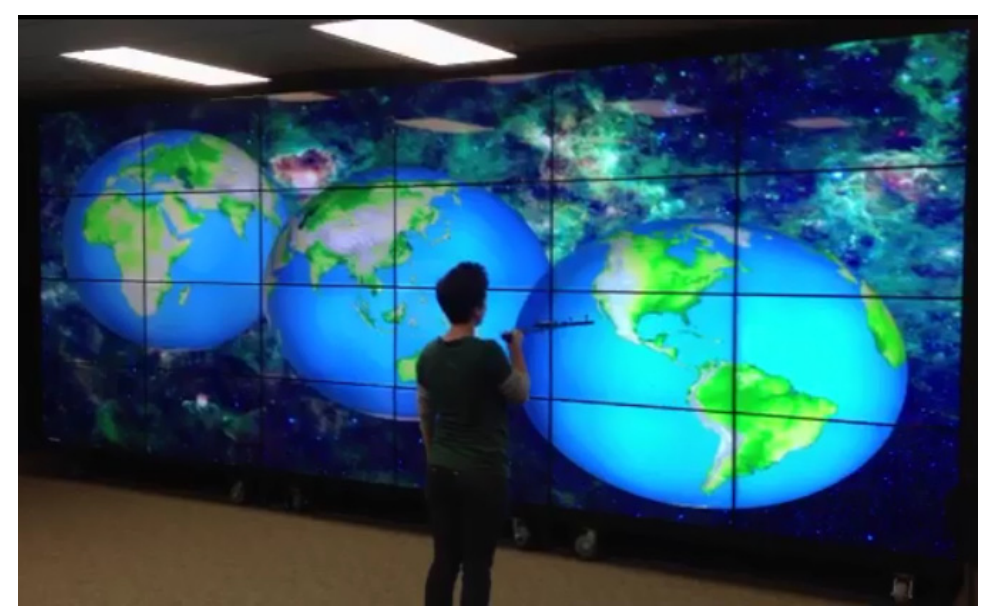

Fig. 2. Users can listen to Michigan Tech introduction in different languages based on their relative location to the world map

Sonification Implementation. The interactive map program takes inputs of the object (in this case, a wand) location from the visualizer program to play Michigan Tech introduction in multiple languages. The location of the wand is kept as an $\mathrm{x}, \mathrm{y}, \mathrm{z}$ point in the Cartesian coordinate, along with the wave file in question that is preprogrammed into the executable. The program then takes the information of the wand's location to determine the amplitude of the wave files that are being played. If the users back up from the display wall, they would hear all voices at a softer level. If the users get closer and point to a certain country, they would hear the introduction in the language that corresponds to the closest country. Depending on the up/down spin orientation of the wand, either male or female voice was amplified and the opposite voice was muted. 


\subsection{Big Instruments}

Overall Concept. Next, we implemented big virtual instruments (e.g., keyboard, percussions, etc) that respond to the users' movements. For example, the display wall show a "Big Piano" (Fig. 3.) on the screen and the user can play the piano by hopping in front of the display wall just as in a famous film, "Big". The sound is generated using the general MIDI with different velocity depending on users' height of hopping. The pressed key is highlighted on the screen accordingly. In the second phase, the sonification system starts to generate real-time sounds using MIDI, which is different from the first phase using prerecorded files. Further, each location contains musically different semantics, frequency information, which is towards a mapping with more continuous variables than in the interactive map.

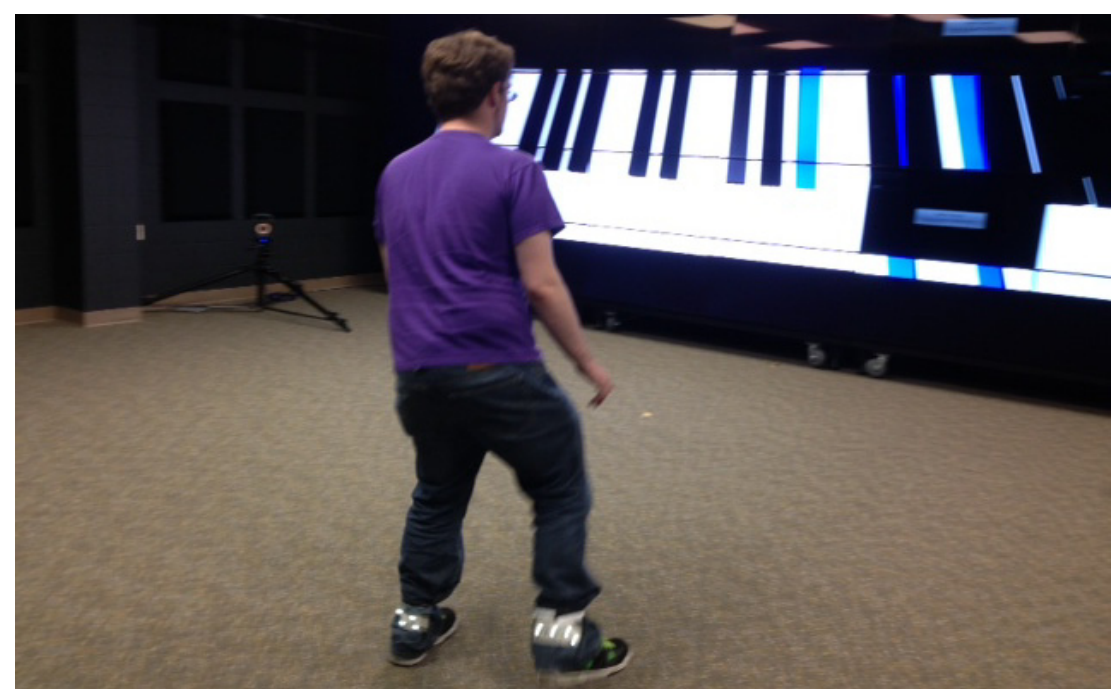

Fig. 3. Users can play big instruments by movements in front of the display wall

Sonification Implementation. This program again receives inputs of the sensing object (e.g., markers of the ankles) locations. In a constants file, it can be updated to take in as many objects as one wishes to track. In other words, several people can play together. Given that an object crosses a pre-defined plane in $\mathrm{z}$ ( $\mathrm{z}$ being from the floor to the ceiling), a sound would play based on the calculated location corresponding to a note, and a calculated velocity based on the current sample and the sample before it (used as a distance covered over time calculation). The instrument was set in the constants file, allowing for easy change of instruments between running the application.

\subsection{Interactive Sonification}

Overall Concept. For a more advanced design research, we have developed a finetuned interactive sonification system in the third phase. In contrast to one-on-one mapping used in the previous two phases, this interactive sonification phase 


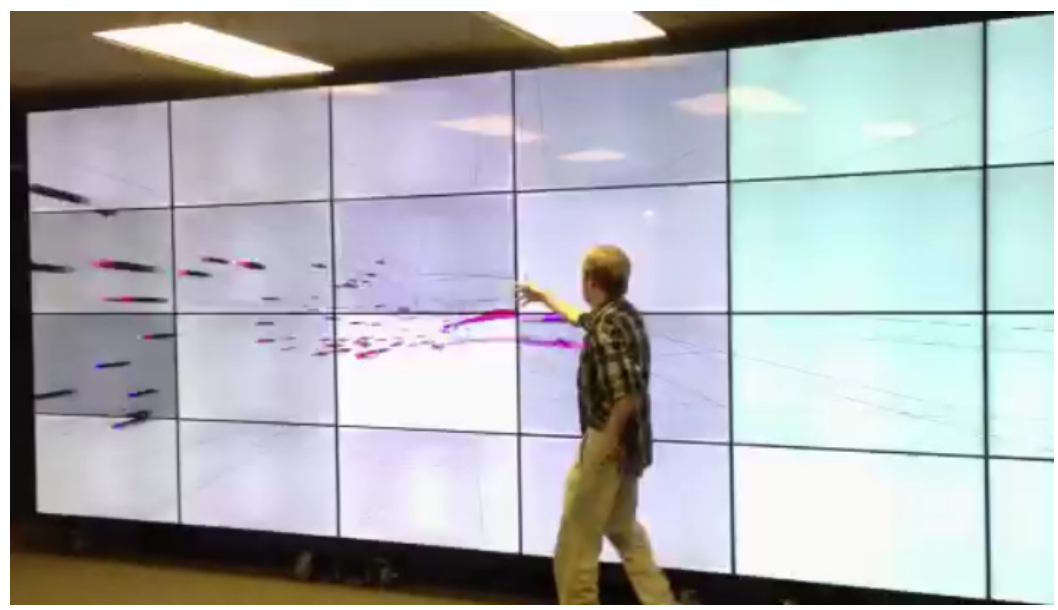

Fig. 4. Users can improvise real-time sonification and visualization based on their location, movement, and gesture. They can change multiple mappings via the scripting language.

allows for many-to-many mappings. In this phase, users can wear a number of trackable objects simultaneously. The positions of these objects are matched with multiple parameters of sonification and visualization systems. For researchers without programming background to configure these mappings, we created a web-based scripting language [for more details, see 26]. Note that we integrated analytical mappings and holistic mappings [e.g., 16]. For example, the system logs time passed, average velocity, and average acceleration (mapping with accumulated time); and proximity to other objects (mapping with the relationship between objects). These holistic mappings are expected to provide an additional aesthetic dimension [see 18] to the real-time sonification and visualization as well as full interactivity [25]. Whereas the first two projects show only responsiveness of the system, the holistic mappings in the third phase enable more interactive communication between the system and users, by reflecting and recurring to the previous messages when generating new messages [see 11].

This system could be used as not only a scientific research platform, but also an experimental artistic performance research platform. Our first on-going project is an interactive ballet performance. Ballerinas can improvise their own music and sound based on their dance, rather than dance based on predefined music. Here, we obtain two different meanings simultaneously: their action (dance) and the conversion of their action into musical meaning [27]. To this end, we have invited ballerinas and analyzed their movements. To extract and analyze key patterns of their movements, we have used video recordings and a cognitive task analysis. Extracted key patterns have informed the sound designers' iterative mapping configurations. The behavioral patterns are being categorized and matched with a certain emotional state [c.f., laban movement 28] and then, will be mapped onto sound profiles accordingly. In addition to real-time art performance, this interactive sonification system can be used for training and learning purposes. The interactive sonification could generate target sounds and guidance sounds to help dancers, instrumentalists, or athletes get to their target behaviors. The visualizer will also help them monitor their own actions. 
Table 2. Example of Sonifier Parameter Mappings in Phase III

\begin{tabular}{|c|c|c|c|c|c|c|c|c|c|}
\hline & $\mathbf{x}$ & $\mathbf{Y}$ & $\mathbf{Z}$ & Velocity & $\begin{array}{l}\text { Acceler } \\
\text { ation }\end{array}$ & $\begin{array}{l}\text { Proxi } \\
\text { mity }\end{array}$ & $\begin{array}{l}\text { Time } \\
\text { passed }\end{array}$ & $\begin{array}{l}\text { Average } \\
\text { velocity }\end{array}$ & $\begin{array}{l}\text { Average } \\
\text { accel. }\end{array}$ \\
\hline Frequency & & $\sqrt{ }$ & & & $\checkmark$ & & & & V \\
\hline $\begin{array}{l}\text { Frequency } \\
\text { Range }\end{array}$ & & & $\sqrt{ }$ & & $\sqrt{ }$ & & & & \\
\hline Panning & $\sqrt{ }$ & & & & & & & & \\
\hline Tonality & & & & & & & $\sqrt{ }$ & & \\
\hline Rhythm & & & & $\sqrt{ }$ & & & & $\sqrt{ }$ & \\
\hline $\begin{array}{l}\text { Rhythmic } \\
\text { Stability }\end{array}$ & & & & & & $\sqrt{ }$ & & & $\sqrt{ }$ \\
\hline $\begin{array}{l}\text { Beat per } \\
\text { Minute }\end{array}$ & & & & & $\sqrt{ }$ & & $\sqrt{ }$ & & \\
\hline Intensity & & & & $\sqrt{ }$ & & & & $\sqrt{ }$ & \\
\hline Instruments & & & $\sqrt{ }$ & & & $\sqrt{ }$ & & & \\
\hline
\end{tabular}

Sonification Implementation. A scripting language (ISML: Interactive Sonification Markup Language, http://cs.mtu.edu/ jwwalker/isml-creator/ISML-Creator.html) was created to allow for researchers to create a script to define how the program would react to positional inputs of worn arm and leg bracelets, etc. The scripting language was implemented to allow for the researchers to define specific events where the sonification mappings have changed. The script also allows for the researchers to generate sounds based on statistics such as position, velocity, acceleration, proximity to other objects, time passed, average acceleration, average velocity, or any equation that uses these inputs to generate an output. Within the implementation of the scripting language, the researchers also have the ability to store values for later use, allowing for almost any event to be described by the scripting language.

Visualization Implementation. The visualization responds to user movements in a number of aspects (Fig. 4). A colored sphere is drawn at the location of each object being tracked. The color of the spheres changes in response to the objects' average proximity to each other, using warmer colors the greater the distance between the objects. Trailing afterimages are rendered for each sphere, with the afterimage elongating the greater the velocity of that object. Each sphere also regularly emits particles which fly in the same direction and velocity as the sphere that created them at the point in time when they were spawned. The background includes multiple intersecting, rotating wireframe spheres whose rotation speed and color are tied to the average velocity of the tracked objects, while the background itself grows brighter and darker in response to tracked objects' average proximity. Transparency effects are used to blend the various visualization components. 


\section{Discussion and Future Work}

Given that interactive sonification has such big potential in a number of research domains, our goal is to make a design research platform that allows researchers to conduct all of the experimental sonification research in a single platform. Before we describe our phased developments in detail, we would first examine design research taxonomy which outlines our design research approaches.

Design can be defined as "a plan for arranging elements in such a way as to best accomplish a particular purpose" [29]. On the other hand, research can be defined as "a systematic investigation that establishes novel facts, solves new or existing problems, proves new ideas, or develops new theories." Taken together, "design research" can be referred to as "the investigation of knowledge through purposeful design." When we agree that sonification is a purposeful mapping between sound and meaning [30] or making an organized sound from the semiotics perspective (Panel discussion at ICAD 2012), the mapping or organizing sound could involve diverse research, aiming at ease of use (perspective of user interface), coaching (perspective of learning and training), or aesthetics (perspective of user experience), depending on its purpose.

Faste and Faste [31] proposed a new framework of the relationship between design and research, and classified design research into four categories: (1) "Design through research" or studious design research is similar to traditional research; (2) "Design of research" or formative design research refers to a meta-process, including the creative activities of planning and preparing for subsequent empirical or theoretical research; (3) In "research on design" or diagnostic design research, researchers investigate their design processes to enhance the future practice of design; and (4) in "research through design" or embedded design research, designers practice their craft to seek new knowledge and to gain insight for the possible outcomes.

All of those four design research approaches have been integrated in our sonification design research using a single platform, iISoP. In other words, (1) Visual, sound, and performing artists and researchers conduct their empirical experiments and based on those research data, they have iteratively redesign their works; (2) Constructing our platform per se can be said as a creative design to prepare for future research design. To this end, we tried to reflect several sonification dimensions (oneon-one mapping vs. many-to-many mapping) and interactivity dimensions (e.g., responsiveness vs. full interactivity) in our phased projects. Accordingly, a project in each phase has been designed in a systematic way for conducting differentiated empirical research; (3) By achieving (2), researchers can look back on and diagnose how they practice their design in terms of goals, variables, and methods. For example, by showing clear distinctions in each project layer, designers can consciously recognize the elements of each layer; and replicate, extend, and combine those ingredients in their future design; (4) Designers' new outcomes can pose unique questions and thus, inspire researchers' future direction again. Therefore, we envision to seeing the harmony and resonance of all these different approaches in our design research platform. 
Planned research projects include training and learning (e.g., instrumentalists and athletes [e.g., 23]) and natural user interfaces for exploring and manipulating large-scale data (e.g., geographical [15] or social networks [16]). Developing a sonification-inspired story-telling system for children is also considered. To investigate "interactivity" further, we plan to conduct a number of studies about the interactions among humans, animals, and robots in the iISoP environment. To devise a fully interactive system, we cautiously review the possibility of anthropomorphism [32] of the iISoP. To this end, it needs to evolve further with higher intellectual capability. Finally, the iISoP could be developed for virtual museums and galleries for better accessibility of audience with diverse disabilities and for enhanced user experience for all populations [11].

\section{References}

1. Jeon, M., Gupta, S., Davison, B.K., Walker, B.N.: Auditory menus are not just spoken visual menus: A case study of "unavailable" menu items. Journal of the Audio Engineering Society 60(7/8), 505-518 (2012)

2. Kramer, G., Walker, B.N., Bonebright, T., Cook, P., Flowers, J., Miner, N.E.A.: The sonification report: Status of the field and research agenda. Report prepared for the National Science Foundation by Members of the International Community for Auditory Display. International Community for Auditory Display (ICAD), Santa Fe (1999)

3. Kramer, G.: An introduction to auditory display. In: Kramer, G. (ed.) Auditory Display: Sonificaiton, Audification, and Auditory Interfaces, pp. 1-77. Addison-Wesley, MA (1994)

4. Hermann, T.: Taxonomy and definitions for sonification and auditory display. In: Proceedings of the 14th International Conference on Auditory Display (ICAD 2008), Paris, France (2008)

5. Hermann, T., Hunt, A., Neuhoff, J.G.E.: The Sonification Handbook. Logos Publishing House, Berlin (2011)

6. Walker, B.N., Kramer, G.: Sonification. In: Karwowski, W. (ed.) International Encyclopedia of Ergonomics and Human Factors, 2nd edn., pp. 1254-1256. CRC Press, New York (2006)

7. Walker, B.N., Kramer, G.: Auditory displays, alarms, and auditory interfaces. In: Karwowski, W. (ed.) International Encyclopedia of Ergonomics and Human Factors, 2nd edn., pp. 1021-1025. CRC Press, New York (2006)

8. Hermann, T., Hunt, A.: The discipline of interactive sonification. In: Proceedings of the International Workshop on Interactive Sonification, Bielefeld, Germany (2004)

9. Hermann, T., Hunt, A.: An introduction to Interactive Sonification. IEEE Multimedia 12(2), 20-24 (2005)

10. Walker, B.N., Kim, J., Pendse, A.: Musical soundscapes for an accessible aquarium: Bringing dynamic exhibits to the visually impaired. In: Proceedings of the International Computer Music Conference (ICMC 2007), Copenhagen, Denmark, August 27-30 (2007)

11. Jeon, M., Winton, R.J., Henry, A.G., Oh, S., Bruce, C.M., Walker, B.N.: Designing interactive sonification for live aquarium exhibits. In: Stephanidis, C. (ed.) HCII 2013, Part I. CCIS, vol. 373, pp. 332-336. Springer, Heidelberg (2013)

12. Jeon, M., Walker, B.N., Bruce, C.M.: Science or art? "Sonification in the age of biocybernetic reproduction": A case study of the accessible aquarium project. In: Proceedings of the International Conference on Auditory Display (ICAD 2013), July 6-10 (2013) 
13. Malizia, A., Bellucci, A.: The artificiality of natural user interfaces. Communications of the ACM 55(3), 36-38 (2012)

14. Jeon, M., Winton, R.J., Yim, J.-B., Bruce, C.M., Walker, B.N.: AquariumFugue: Interactive sonification for children and visually impaired audience in informal learning environments. In: Proceedings of the 18th International Conference on Auditory Display, ICAD $2012(2012)$

15. Zhao, H., Smith, B.K., Norman, K., Plaisant, C., Shneiderman, B.: Interactive sonification of choropleth maps. IEEE Multimedia 12(2), 26-35 (2005)

16. Hermann, T., Bovermann, T., Riedenklau, E., Ritter, H.: Tangible computing for interactive sonification of multivariate data. In: International Workshop on Interactive Sonification (ISon), York, UK. (2007)

17. Stockman, T.: Interactive sonification of spreadsheets. In: Proceedings of the International Conference on Auditory Dislay (ICAD 2005), Limerick, Ireland, pp. 134-139 (2005)

18. Fernström, M., Brazil, E., Bannon, L.: HCI Design and interactive sonification for fingers and ears. IEEE Multimedia 12(2), 36-44 (2005)

19. Antle, A.N., Droumeva, M., Corness, G.: Playing with the sound maker: Do embodied metaphors help children learn? In: Proceedings of the Conference on Interaction Design and Children, Chicago, IL, USA, pp. 178-185 (2008)

20. Ferguson, S.: Learning musical instrument skills through interactive sonification. In: International Conference on New Interfaces for Musical Expression (NIME 2006), pp. 384-389 (2006)

21. Howison, M., Trninic, D., Reinholz, D., Abrahamson, D.: The mathematical imagery trainer: From embodied interaction to conceptual learning. In: Proceedings of the SIGCHI Conference on Human Factors in Computing Systems (CHI 2011), Vancouver, BC, Canada, pp. 1989-1998 (2011)

22. Hermann, T., Zehe, S.: Sonified aerobics: Interactive sonification of coordinated body movements. In: Proceedings of the International Conference on Auditory Display (ICAD 2011), Budapest, Hungary (2011)

23. Schaffert, N., Mattes, K., Effenberg, A.O.: The sound of rowing stroke cycles as acoustic feedback. In: Proceedings of the International Conference on Auditory Display (ICAD 2011), Budapest, Hungary (2011)

24. Walker, B.N., Godfrey, M.T., Orlosky, J.E., Bruce, C., Sanford, J.: Aquarium sonification: Soundscapes for accessible dynamic informal learning environments. In: Proceedings of the Conference on Auditory Display (ICAD 2006), London, UK, pp. 238-241 (2006)

25. Rafaeli, S.: Interactivity: From new media to communication. Sage Annual Review of Communication Research: Advancing Communication Science 16, 110-134 (1988)

26. Landry, S., Jeon, M., Ryan, J.: A broad spectrum of sonic interactions at immersive interactive sonification platform (iISoP). In: Proceedings of the 21st IEEE Virtual Reality Conference (Workshop in Sonic Interactions in Virtual Environments), Minneapolis, Minnesota (2014)

27. Roddy, S., Furlong, D.: Emobided cognition in auditory display. In: Proceedings of the International Conference on Auditory Display (ICAD 2013), Lodz, Poland (2013)

28. Camurri, A., Lagerlöf, I., Volpe, G.: Recognizing emotion from dance movement: Comparison of spectator recognition and automated techniques. International Journal of Human-Computer Studies 59, 213-225 (2003)

29. Neuhart, J., Neuhart, M., Eames, R.: Eames Design: The work of the office of Charles and Ray Eames. Harry N. Abrams, New York (1989) 
30. Jeon, M.: Two or three things you need to know about AUI design or designers. In: Proceedings of the International Conference on Auditory Display (ICAD 2010), Washington D.C. (2010)

31. Faste, T., Faste, H.: Demystifying "design research": Design is not research, research is design. In: Proceedings of the IDSA (2012)

32. Le Groux, S., Manzolli, J., Verschure, P.F.M.J.: Interactive sonification of the spatial behavior of human and synthetic characters in a mixed-reality environment. In: Proceedings of the 10th Annual International Workshop on Presence, pp. 27/388-34/388 (2007) 